\title{
Conditions on the Application of Sprayable waterproofing Membrane in Tunnels under Sulfate Attack Environments
}

\author{
Jianqin $\mathrm{Ma}^{1, \mathrm{a}}$ \\ ${ }^{1}$ Highway School, Chang'an University, the Middle Section of the Second South Ring, Xi'an, China \\ a majq@gl.chd.edu.cn
}

Keywords: Spray-on waterproofing membrane; Sulfate attack environment; Application conditions; Tunnel.

Abstract. Spray-on membrane is a new waterproofing system in tunnels. The conditions of the application of this system under sulfate attack environments are analyzed in terms of the deformation and surface condition of the first layer of the shotcrete shell, water ingress and water pressure behind the waterproofing membrane; as well as the mechanism of sulfate attack in concrete, the features of the interaction of the sulfate bearing ground water with shotcrete linings. The results show that the applications of a spray-on waterproofing membrane in a tunnel is possible if the deformation, the durability and specification of materials of the shotcrete and water pressures behind the sprayed membrane are properly controlled. Measures to meet the conditions are presented for the application of the membranes in tunnels.

\section{Introduction}

Tunnel and underground structures are increasingly constructed since 1970s. The ingress of water from wall rocks should be controlled, though the restriction level of the water ingress may be variable. The waterproofing of tunnels is often a key problem and various solutions, e.g., PVC and HDPE sheet membranes, have been conventionally used to provide a dry structure. In recent years, spray-on waterproofing membrane has been used in some tunnels[1][2]. For tunnels with shotcrete lining, the advantages of a sprayable membrane are significant, such as in terms of cost and time schedule [1][3]. Considering its popularization in the future, a design guidance[3] was proposed by ITAtech Activity Group in 2013. However, concrete is vulnerable to the aggressive ions. Sulphate ions in the presence of moisture can change the chemical composition of the cement matrix. Concrete deterioration by sulphate attack at tunnel sites were reported in recent years[4][5], due to leaching and the formation of sulfate minerals, such as ettringite and thaumasite[6][7]. The sulphate attack in shotcrete lining can result in a significant decrease of the concrete stability[8]. This paper presents the conditions of the application of sprayable waterproofing membrane system under sulfate attack environments. Measures to meet the conditions are also presented for the application of the membrane in tunnels.

\section{Structures and main properties of spray-on waterproofing membrane}

The spray-on waterproofing membrane, e.g., the Masterseal 345 and 340F, is based on an ethylene-vinyl acetate copolymer, mixed with small quantity special cement. It requires only water as a mixing agent and is applied using the shotcreting crews and equipment, introduced water to the dry-mix at the nozzle of the spraying boom. In practice, the use of maximum $8 \mathrm{~mm}$ aggregate in shotcrete is sufficient for the substrate preparation of the membrane application. In structure, the spray-on membrane in a shotcrete lining is sandwiched between shotcrete layers (Fig. 1). Similar to the application of dry-process shotcrete, the sprayed membrane can only be directly applied on relatively dry surface. Systematic or targeted geotextile fleece is used in areas of direct water ingress, in order to allow the product to dry and to control active water flow from substrate (Fig. 1a).

Where there is no geotextile fleece, the membrane bonds mechanically and chemically to the shotcrete on both sides (Fig. 1b). The sprayed membrane can work as a structure in shotcrete linings[1]. The membrane itself needs a minimum thickness of $2 \mathrm{~mm}$ in order to be watertight. In 
practice, the designed thickness of the sprayed membrane is usually 3 to $4 \mathrm{~mm}$. The main features of sprayed-on waterproofing membrane layer in a composite shotcrete lining is shown in Table 1.

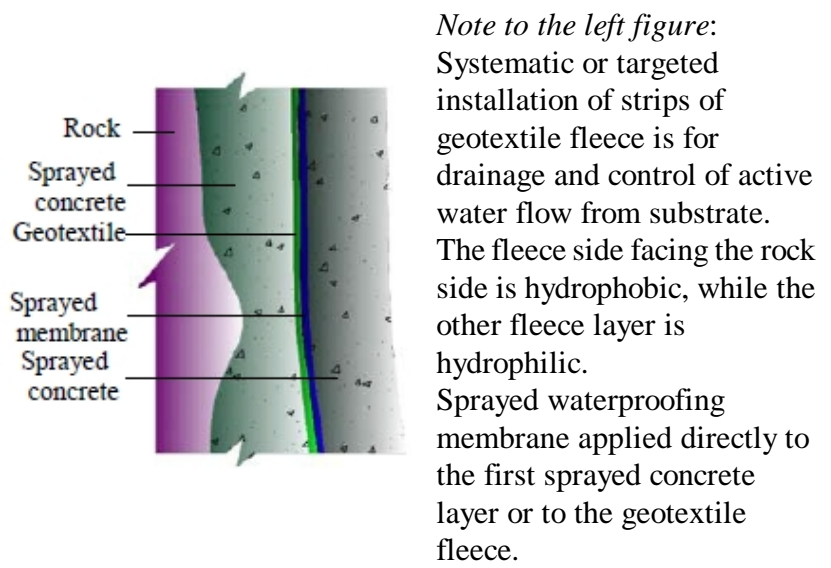

(a) Simplified sprayed membrane in tunnel structures

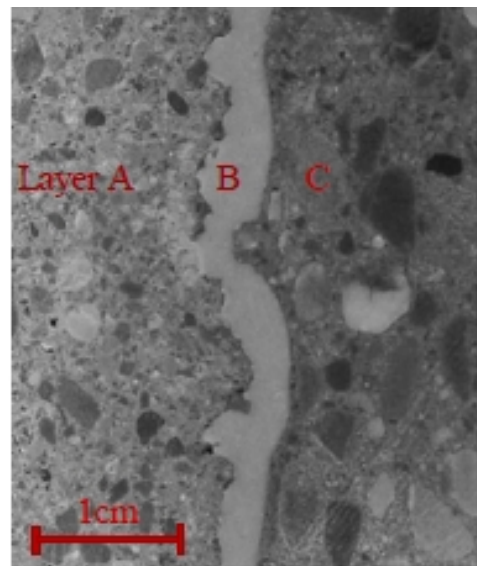

Note to the left figure: The layer A shows the substrate (rock support) sprayed concrete. The layer B is the spray-on waterproofing membrane. The layer $\mathrm{C}$ shows the inner lining sprayed concrete which is covering the spray-on waterproofing membrane. The layers $\mathrm{A}$ and $\mathrm{C}$ are partially shown.

(b) Sprayed membrane in practical case (modified from[1]) Fig. 1. Structure of Sprayed Waterproofing Membrane in Single Shell Linings

Table 1. Main Features of Sprayed-on Waterproofing Membrane in a Tunnel Lining

\begin{tabular}{|c|c|c|c|}
\hline Item No. & \multicolumn{2}{|l|}{ Main technical property } & Typical value \\
\hline 1 & Dimension & Minimum membrane thickness* & $2 \mathrm{~mm}$ \\
\hline 2 & \multirow{5}{*}{ Mechanical properties } & Elongation failure strain (at $+20^{\circ} \mathrm{C}$, at 28 days) & $100 \%$ \\
\hline 3 & & Tensile failure stress (at $+20^{\circ} \mathrm{C}$, at 28 days) & $>2 \mathrm{MPa}$ \\
\hline 4 & & Membrane-concrete interface tensile strength ( 28 days) & $>1 \mathrm{MPa}$ \\
\hline 5 & & Shear strength**, planar interfaces, JRC $=0$ & $1 \mathrm{MP} \mathrm{a}$ \\
\hline 6 & & Shear strength $* *$, rough surfaces, JRC $=20$ & $1.7 \mathrm{MPa}$ \\
\hline 7 & Permeability & Water pressure resistance (max) & $1.5 \mathrm{MPa}$ \\
\hline 8 & Working condition & Application temperature & $+5^{\circ} \mathrm{C}$ to $+40^{\circ} \mathrm{C}$ \\
\hline 9 & Leak repair & Repair easily at leak location & 1 \\
\hline 10 & Fibre interaction & Fibres encapsulated & I \\
\hline
\end{tabular}

Note: Based on sprayed concrete and Masterseal®345, from [1], information from www.meyco.basf.com; * All tests refer to this minimum membrane thickness; ** Shear strength of entire composite structure.

To meet the design requirement of a bonded membrane between the two layers of sprayed concrete acting as one structure for the entire lining thickness, the tensile bonding strength of the membrane-concrete interfaces should not be significantly lower than the tensile bonding strength between the rock surface and the sprayed concrete. In the ITAtech Design Guidance[3], a magnitude of no less than $0.5 \mathrm{MPa}$ is proposed for the tensile bonding strength of the sprayed membranes to shotcrete layer.

In practical tunnel, the failure of the membrane depends on the deformation of the shotcrete layers. Shotcrete failure mechanism is a combination of adhesion loss and flexural failure. For example, the shotcrete capacity in blocky ground is governed by four mechanisms, i.e., adhesion loss, direct shear, flexural failure or punching shear[9]. For the shear circumstance, the deformation of the shotcrete and wall rocks should be controlled to in specified range, e.g., the local strain being less than $100 \%$. The sprayed membrane can bridge small cracks in the shotcrete. The case histories indicated that the sprayed membrane can cope with crack widths equal to its thickness[1]. The recent case studies[10] gave similar results.

The properties of sprayed-on waterproofing membrane is strongly related to the composition of the mixtures of the waterproofing membrane. The recent results[10] shows that the membrane products with low polymeric content (e.g., below $70 \%$ ) exhibit low elasticity and are likely unsuitable for tunnel waterproofing purposes.

\section{Water flow paths and pressures behind the sprayed membrane}

In order to decrease water pressure thrusting on the waterproof layer in a tunnel structure, the pressure 
is often controlled, e.g., through leading the water from the rock into a subsurface draining system, decreasing the permeability of the wall rocks by grouting. Seepage points can be handled using drainage pipe before sprayed concrete and waterproof membrane construction.

Water leakage is often caused by cracks in the shotcrete, bad workmanship and porous shotcrete. The sprayed waterproof membrane should have the capacity of resisting the water pressure in the case of relatively permeable shotcrete. The water pressure depends on the relative wall rocks-lining stiffness, relative wall rocks-lining permeability, and geometric factors[11]. For example, in drained conditions, water pressure of lining loads can be significantly reduced due to seepage forces. For high quality shocrete, with the coefficient of water permeability of $1 \times 10^{-14} \mathrm{~m} / \mathrm{s}$, water ingress in shotcrete layer is generally not through the shotcrete itself, but the joints and weak points in it.

The sprayed membrane can forms a structural bond to adjoining shotcrete layers. The water resisting strength of the membrane (Table 1) can generally meet the design specified target. This bonding property makes the interface between membrane and concrete impermeable and significantly reduces water travel along the exterior of the membrane as shown in Fig. 2. This feature makes the sprayed membrane different from the conventional waterproofing systems with a sheet membrane (Fig. 2). In the sprayed membrane, an eventual seepage point through the membrane can be resolved locally, exactly where the seepage occurs. Since this point corresponds to the seepage channel in the concrete behind the membrane, it is easier to repair at leak location.

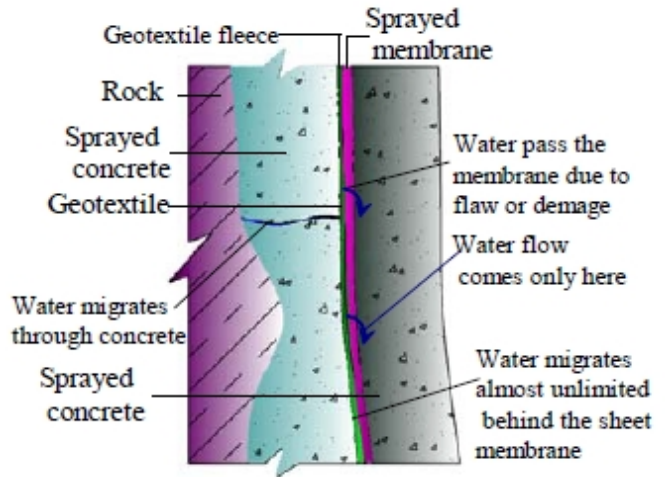

(a) Water flow path in a single shell lining with sprayed waterproofing system

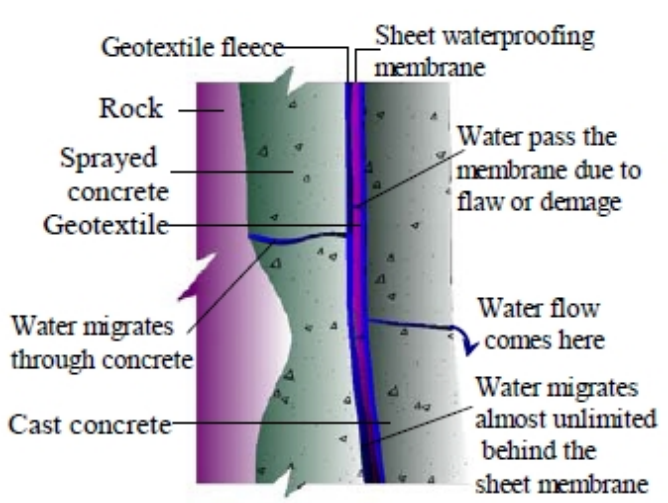

(b) Water flow path in a conventional composite lining system

Fig. 2. Comparison of Water Flow Paths in Conventional Composite System and Single Lining

\section{Mechanisms of sulfate attack in concretes}

The shotcrete linings in tunnels are vulnerable to sulfate attack. The deterioration of shotcrete linings is triggered by permeable inhomogeneities, which serve as pathways for the percolating water. The sulfate attack due to thaumasite formation can significantly damage to the paste matrix as C-S-H replaced by thaumasite. For tunnel shotcrete linings, small amounts of shotcrete alteration at the interface between the lining and wallrocks can lead to significant reduction of adhesion and risk of detachment[4][5]. However, the sulfate content in ground water samples from the situations showing thaumasite attack in shotcrete may be low and hardly aggressive in current standards[6]. More attention should be paid to this kind of sulfate attack.

Conventionally, sulfate attack in concretes involves the formation of expansive sulfate phases like ettringite and gypsum. The formation of thaumasite can occur if the cement and concrete contain a source of carbonate[12][13]. According to the source of the sulfate, the types of sulfate attack are external and internal sulfate attacks. External sulfate attack (ESA) usually occurs when environmental sulfate penetrates into a concrete structure. Internal sulfate attack occurs where sulfate ions release from either cement or gypsum-contaminated aggregates. Here only the ESA in shotcrete will be discussed.

Of the ESA in concrete, the deterioration of concrete is the result of the penetration of aggressive agents into the concrete and their chemical reaction with the cement matrix. The main 
reactions[14][15] are: (a) the degradation of C-S-H, and (b) the decalcification of the cement paste hydrates upon sulfate ingress or sulfate attack on $\mathrm{C}-\mathrm{S}-\mathrm{H}$ and $\mathrm{CH}$ in the presence of carbonate ions to form thaumasite. These chemical reactions can lead to cracking of concrete, and/or the loss of strength and elastic properties of concrete. The processes of both diffusion and reaction may control the sulfate attack mechanism ${ }^{[14]}$. For example, the formation of thaumasite is controlled by the diffusion of carbonates and sulphates in the shotcrete, and is also controlled by the solubility of gas $\mathrm{CO}_{2}$ in water.

Tixier and Mobasher (2003) [14] showed that some sulfate attack models have chosen diffusivities between $0.75 \times 10^{-12}$ and $9 \times 10^{-12} \mathrm{~m}^{2} / \mathrm{s}$; following the values of the intrinsic sulfate diffusivity in concrete, the sulfate diffusivities are about $1.0 \times 10^{-11}$ to $3.5 \times 10^{-11} \mathrm{~m}^{2} / \mathrm{s}$ for $\mathrm{w} / \mathrm{c}=0.45$ to 0.65 . As the effect of sulfate attack on the value of the porosity of the cement paste is considered, it is estimated that the diffusivity of a paste can be increased by at least an order in magnitude. Another indirect approach is relating intrinsic ionic diffusivity to the water permeability coefficient, and sulfate diffusivities are in the range of $2 \times 10^{-12}$ to $20 \times 10^{-12} \mathrm{~m}^{2} / \mathrm{s}$.

For the sulfate attack in tunnel shotcrete, the sources of $\mathrm{CO}_{3}{ }^{2-}$ ions, $\mathrm{CaO}$ and $\mathrm{H}_{2} \mathrm{O}$ are usually abundant. The source of $\mathrm{CaO}$ is abundant in Portland cement concrete. $\mathrm{The}_{2} \mathrm{H}_{2} \mathrm{O}$ is from wallrocks. Sources of $\mathrm{SO}_{4}{ }^{2-}$ ions include groundwater in sulfate or sulfide bearing ground, contaminated aggregates. The oxidation of the sulfides not only produce $\mathrm{SO}_{4}{ }^{2-}$ ions erosive groundwater, but also cause environmental medium $\mathrm{pH}$ decline and turns the environment from reductive state to oxidized state.

\section{Interaction of corrosive ground water with shotcrete linings}

As the above mentioned that the sulfate attack in shotcrete occurs as the percolating of sulfate solution in the structure. For the tunnels, with conventional water drainage and proofing system, tunnel sites generally provide a great potential for concrete corrosive processes. However, the linings, with sprayed on waterproof membrane, are saturated with water only in few areas and water is penetrating the shotcrete locally, e.g., along joints and cracks. Water moves along local and permeable inhomogeneities through the shotcrete lining[4][6]. Cement paste dissolution and erosion may lead to loss of adhesion between shotcrete and rocks. The back side of shotcrete lining is more prone to corrosion. Fig. 3a shows schematically locations within the cross section where concrete degradation due to interaction with ground water percolating. The degradation generally varies in their intensities over time and even within short distance.

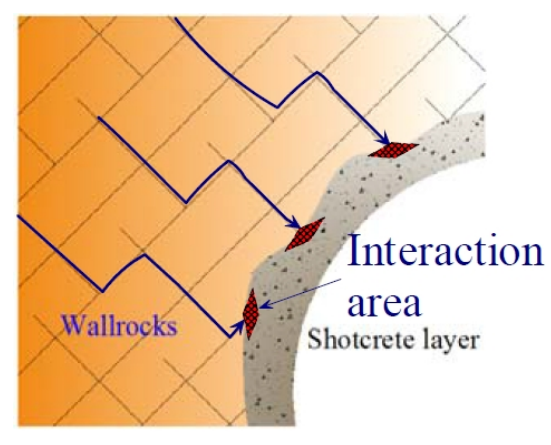

(a) Groundwater water percolating

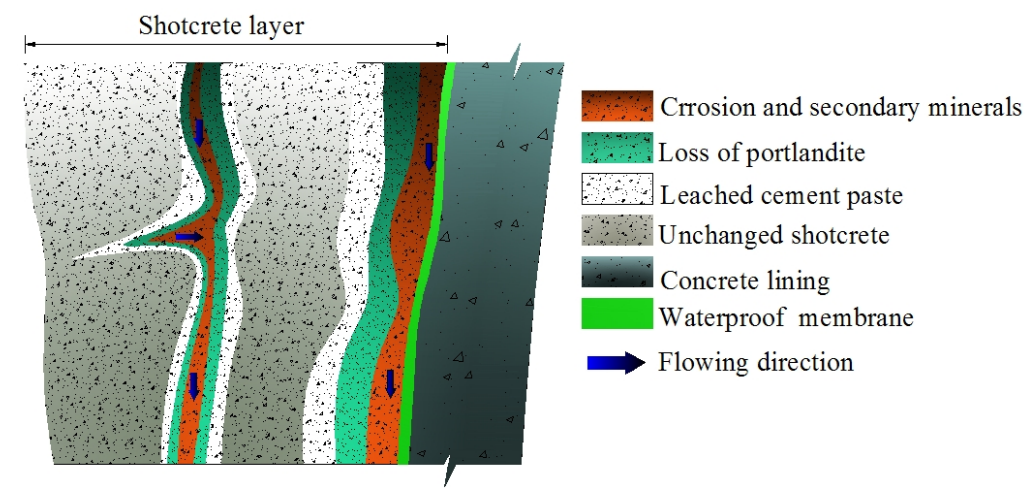

(b) Interaction and formation of alteration zone

Fig. 3. Shotcrete Lining with Local Water Percolating and the Formation of Alteration Zones

Sulphate attack to hydraulic concrete involves a series of possible physicochemical processes that are evidenced through deterioration of the material[4][6]. The sulfate attack in shotcrete can be generally considered as sulphate attack by alkali sulfates and thaumasite form of sulfate attack in terms of chemical reaction and the formation of secondary minerals. The case histories on sulfate attack in shotcrete linings showed that the attack is triggered by permeable inhomogeneities which serve as pathways for the percolating water, and the zonations of leaching and thaumasite formation occur along the pathway[6][16][17]. The alteration and interaction zonations are mainly along the contact to 
the shotcrete and lesser along the layer contacts within the concrete[6]. The alteration increases from the unchanged shotcrete to the above mentioned contacts. The alteration may include several distinct zones, as shown in Fig. 3b. The zone of leached cement paste is followed by the lack of portlandite and there is a general grain size reduction of cement phases. The corrosion zone is characterized by complete dissolution of cement paste and more or less intensive formation of secondary phases resulting in a highly porous and mechanically weak material. The transitions between the regions of different state of alteration are quite sharp. The stability of hydration products in hardened shotcrete depends on the chemical composition of the pore solution which itself is chemically buffered by the hydration products[13][14]. The interaction with an aqueous environment usually results in the formation of a zonation pattern, with the diffusion flux along boundary into both sides[18]. A typical corrosive process include dissolution of cement phases, transportation of dissolved chemical species and (re-)precipitation of secondary minerals. The water flow through a crack is always leading to leaching of the crack walls, as shown in Fig. $3 b$.

\section{Basic requirements to cope with the sulfate attack in shotcrete}

The waterproofing of aggressive ground water is one of the main factors related to both operation reliability and durability of tunnels. Sulfate resistance of the concrete is mainly related to its physical and chemical resistance to penetrating sulfate ions[14]. To ensure good physical and chemical resistance of the concrete to limit the penetrating sulfate ions, low permeability concrete is the best defense. In general, the standards that regulate the use of Portland cement in aggressive sulphates ambient, limit the content of aluminates in cements in order to avoid formation of expansive ettringite. However, no prevention is considered regarding the destructive action on concrete from possible thaumasite formation. Special requirement should be considered in the design of sulfate attack resisting shotcrete. The wet process with appropriate workability time of a low w/c ratio concrete mix is a technology direction[19]. Some basic requirements for the properties of sulfate attack resisting shotcrete are presented in Table 2.

Table 2. Properties of Sulfate Attack Resisting Wet Process Shotcrete

\begin{tabular}{|l|l|l|l|}
\hline Item No. & Main technical property & Typical value \\
\hline 1 & \multirow{2}{*}{ Addimixture } & Accelerator & About $8 \%$ in weight of cement \\
\cline { 3 - 4 } & & Coarse aggregate & maximum $8 \mathrm{~mm}$ \\
\hline 2 & w/c ratio & w/c ratio & $<0.45$ \\
\hline 3 & \multirow{2}{*}{ Strength at 28 days } & Compressive strength & $>40 \mathrm{MPa}$ \\
\cline { 4 - 4 } & & Flexural strength & $>4.5 \mathrm{MPa}$ \\
\hline 4 & \multirow{3}{*}{ Permeability } & Coefficient of water permeability, $\mathrm{K}$ & $<1.8 \times 10^{-12} \mathrm{~m} / \mathrm{s}$ \\
\cline { 4 - 4 } & & Impermeability DIN 1048 & penetration $<20 \mathrm{~mm}$ \\
\cline { 3 - 4 } & & Rapid sulfate permeability & $<1750$ Coulombs \\
\hline 7 & & & \\
\hline 8 & & &
\end{tabular}

Note: Based on information from[14][19][21].

In technology, the wet process can produce sulfate attack resisting shotcrete, in terms of sulfate diffusivity as well water percolating. Sulfate-resisting concrete can be achieved using a sufficient quantity of sulfate-resisting cement and a low water-cement ratio to obtain a concrete with low water permeability[20]. The current shotcrete technology, for the low hydration heal cement, additives for low porosity, $\mathrm{K}$ is about $10^{-14} \mathrm{~m} / \mathrm{s}[21]$. This means that the present wet process technology can meet the basic requirements of the sulfate attack resisting shotcrete. However, the quality control of shotcrete must be reinforced at all levels of management right through the operations to the nozzle-man at the face, since the sulfate attack usually occurs at the lower quality locations. All these factors, such as specifications, mix design, testing, training, equipment, logistics, application, quality control, and commitment must be well addressed[19]. Furthermore, it should be noted that there are variations within the main components between tunnels, and site test is always beneficial. For example, a few laboratory tests on the influence of alkali free accelerators (AFA) on sulfate resistance of mortar 
specimens[22] showed that the mortar specimens with AFA were susceptible to sulfate deterioration. This suggests that AFA may lead to a poor sulfate resistance. A special care should be taken when the shotcrete with AFA application under the sulfate-rich environments.

\section{Conclusion}

For tunnels with shotcrete lining, the advantages of a sprayable membrane are significant in terms of construction, structure and waterproof effectness. The applications of a spray-on waterproofing system in a tunnel under sulfate attack environment are possible provided that the construction and deformation of the shotcrete, and water pressures behind the sprayed membrane are properly controlled. Special attention should be paid to the AFA application under sulfate-rich environments. The quality control of the shotcrete should be reinforced in addimixture design and at all levels of management right through the operations to the nozzle-man at the face.

\section{References}

[1] K F. Garshol, in: Proc. of Waterproofing, Sao Paulo, 2005, SP7.

[2] K G. Holter, B. Nermoen, in: Proc. of WTC 2011, Helsinki, Finland, 2011.

[3] ITAtech Activity Group, ITAtech Report No 2. International Tunneling Association, 2013, 64p.

[4] M. Romer, L. Holzer, M. Pfiffner: Cement \& Concrete Composites 2003, 25, 1111-1117.

[5] F. Mittermayr, D. Klammer, C. Bauer, M. Dietzel, S.J. Köhler, A. Leis, in: Proc. of DMG, Berlin, 2008, S. 1-2

[6] M. Romer, in: Proc. of Int. Seminar on the Thaumasite Form of Sulfate Attack on Concrete, Sheffield, UK, 2003.

[7] S.T. Lee, R.D. Hooton, H.J. Jung, D.H. Park, C.S. Choi: Cement \& Concrete Research 2008, 38: 68-76.

[8] F. Bellmann, J. Stark: Cement \& Concrete Research 2007, 37: 1215-1222.

[9] S.V.L. Barrett, D.R. McCreath: Tunnelling \& Underground Space Technology 1995, 10: 79- 89.

[10] K. G. Holter: Rock Mech Rock Eng (2016) 49:1329-1358.

[11]W. Bilfinger, in: Proc. of Waterproofing, Sao Paulo, 2005, SP19.

[12] S. Köhler, D. Heinz, L. Urbonas: Cement \& Concrete Research 2006, 36: 697-706.

[13] Th. Schmidt, B. Lothenbach, M. Romer, K. Scrivener, D. Rentsch, R. Figi: Cement \& Concrete Research 2008, 38: 337-349.

[14]R. Tixier, B. Mobasher: J. Mater. Civ. Eng. 2003, 15(4): 314-322.

[15]CCAA, Cement Concrete \& Aggregates Australia, Sep 2007.

[16]P. Hagelia, R.G. Sibbick, N.J. Crammond, A. Grønhaug, C.K. Larsen, in: Proc. of the 8th Euroseminar on Microscopy Applied to Building Materials, Athens, Greece, 2001, 131-138.

[17]R.G. Sibbick, N.J. Crammond, in: Proc. of the 8th Euroseminar on Microscopy Applied to Building Materials, Athens, Greece, 2001, 261-269.

[18]E. Samson, J. Marchand, J.J. Beaudoin: Cement \& Concrete Research 2000, 30: 1895-1902.

[19] M. Rispin, D. Howard, O.B. Kleven, K. Garshol, J. Gelson, in: Proc. of the SRDM 2009, Perth, Australia, 69-81.

[20] S.P. Lee, D.H. Kim, J.H. Ryu, J.Y. Yu, S.D. Lee, S.H. Han, M.S. Choi, in: Proc. of the 31st WTC 2005, 1: 455-461.

[21]T.B. Celestino, in: Proc. of Waterproofing, Sao Paulo, 2005, SP1.

[22] S.T. Lee, D.G., Kim, H.S. Jung: Journal of Civil Engineering 2009, 13: 49-54. 